\title{
Subtalar Dislocations: Case Series Inclusive of the Rare Anterior Subtalar Dislocation and Review of the Literature
}

\author{
D Clarke ${ }^{1}$, S Franklin², S Mullings ${ }^{2}$, K Vaughan ${ }^{1}$, K Jones $^{2}$
}

\begin{abstract}
Subtalar dislocations were first described by Judey and Dufaurest in 1811. These dislocations represent only 1-2\% of all joint dislocations, making them a rare injury. In this rare injury, there are four variations with differing clinical presentations. The clinical picture may vary from a dramatic deformity (as in medial and lateral dislocations) to a more subtle presentation (as in anterior and posterior dislocations). This case series highlights the variations in clinical presentations and the management difficulties associated with each subtype.
\end{abstract}

Keywords: Anterior subtalar dislocation, lateral subtalar dislocation, medial subtalar dislocation, subtalar dislocation

\section{Dislocaciones subtalares: serie de casos con inclusión de la rara dislocación subtalar anterior y revisión de la literatura \\ D Clarke', S Franklin², S Mullings², K Vaughan ${ }^{1}$, K Jones $^{2}$}

\begin{abstract}
RESUMEN
Las dislocaciones subtalares fueron por primera vez descritas por Judey y Dufaurest en 1811. Estas dislocaciones representan solamente el 1-2\% de todas las dislocaciones de las articulaciones, por lo que constituye una lesión poco frecuente. Esta rara lesión se caracteriza por cuatro variaciones con presentaciones clínicas que difieren. El cuadro clínico puede variar desde una deformidad dramática (tal cual ocurre en las dislocaciones intermedias y laterales) hasta una presentación más sutil (como en el caso de las dislocaciones anteriores y posteriores). Esta serie de casos destaca las variaciones en las presentaciones clínicas y las dificultades en el tratamiento asociado con cada subtipo.
\end{abstract}

Palabras clave: Dislocación subtalar anterior, dislocación subtalar lateral, dislocación subtalar medial, dislocación subtalar

From: ${ }^{1}$ Division of Orthopaedic Surgery, Department of Surgery, Radiology, Anaesthesia and Intensive Care, University Hospital of the West Indies, Kingston, Jamaica, West Indies and ${ }^{2}$ Department of Orthopaedic Surgery, Mandeville Regional Hospital, Manchester, Jamaica, West Indies.
Correspondence: Dr D Clarke, Division of Orthopaedic Surgery, Department of Surgery, Radiology, Anaesthesia and Intensive Care, University Hospital of the West Indies, Kingston 7, Jamaica, West Indies. Email: daineoclarke@gmail.com 


\section{INTRODUCTION}

Subtalar dislocations represent a complex dislocation of the talonavicular and talocalcaneal joints while the tibiotalar and calcaneocuboid joints remain intact, without an associated fracture of the neck of the talus $(1,2)$. They are a relatively rare injury, accounting for $1-2 \%$ of all joint dislocations (3). Subtalar dislocations are frequently associated with fractures of the surrounding bones, in particular, the fifth metatarsal, lateral malleolus and talus. The clinical presentation is often dramatic with a significant amount of deformity. The majority of these dislocations can be successfully reduced in an emergency setting with closed manipulation. However, closed reduction may be impeded at times by surrounding soft tissue structures, necessitating open reduction. The long-term sequelae are quite unpredictable, and there is no consensus regarding the period of immobilization that is necessary post-reduction.

Four case reports are presented here, including the rare anterior subtalar dislocation. To our knowledge, only 13 cases of the anterior subtalar dislocation are reported in the literature and of these 13, few are substantiated with the requisite radiographs (4-8). The variations in associated injury patterns and management difficulties that may arise are highlighted.

\section{CASE REPORT}

\section{Case 1}

A 49-year-old woman slipped and fell while descending a flight of stairs, sustaining trauma to her right ankle and foot. She complained of pain, swelling and deformity to her foot. On examination, there was gross varus deformity of the foot. A neurovascular examination revealed a normal neurological examination, but the dorsalis pedis pulse was reduced compared to the contralateral limb. Radiographs revealed a medial dislocation of the talonavicular joint and talocalcaneal joint with an intact tibiotalar joint. No fractures were appreciated (Fig. 1).

A diagnosis of a medial subtalar dislocation was made, and closed reduction under conscious sedation was performed in the emergency room. An audible clunk was heard as reduction was achieved and confirmed by post-reduction films (Fig. 2). The foot was immobilized with a dorsal splint, which was converted to a short leg cast five days post-injury. The limb remained immobilized for three weeks. Active range of motion was commenced, and the patient was allowed to weight-bear partially at four weeks. Full weight-bearing was allowed at eight weeks.
At her last outpatient visit, 18 months post-injury, she had pain-free ambulation, despite limitations in the range of motion at her subtalar joint.

\section{Case 2}

A 39-year-old man lost control of his motorcycle that collided in a tree, resulting in him sustaining trauma to his right foot. He immediately noticed deformity to his right foot and experienced severe pain. When he was seen in the accident and emergency department, a varus deformity of the right foot was noted with tenting of the skin over the lateral malleolus (Fig. 3A). He had no distal neurovascular deficit. Plain radiographs were done which revealed a medial dislocation of the talonavicular joint and talocalcaneal joint with an intact tibiotalar joint. No fractures were observed (Figs. 3B-D).

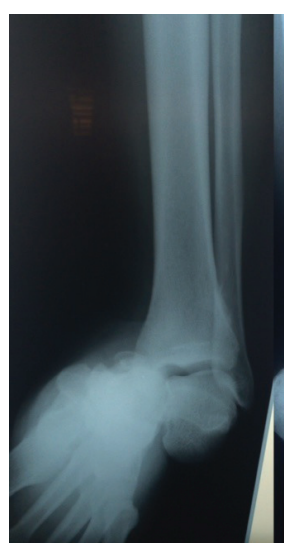

A

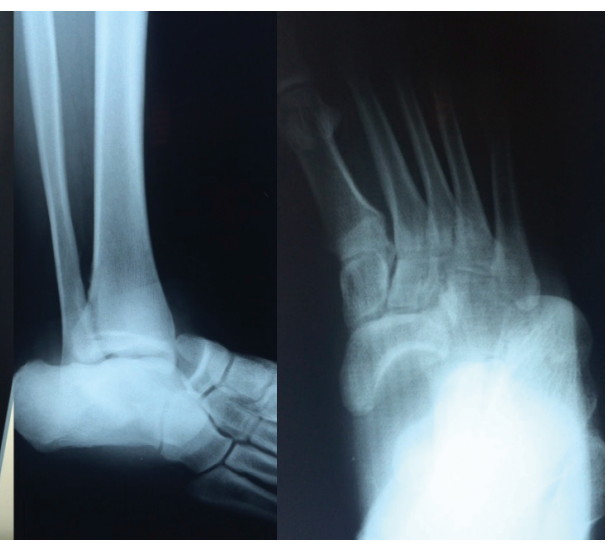

B
C
Fig. 1: Radiographs of the right ankle: anterior-posterior view (A), lateral view (B), anterior-posterior view of the right foot (C).

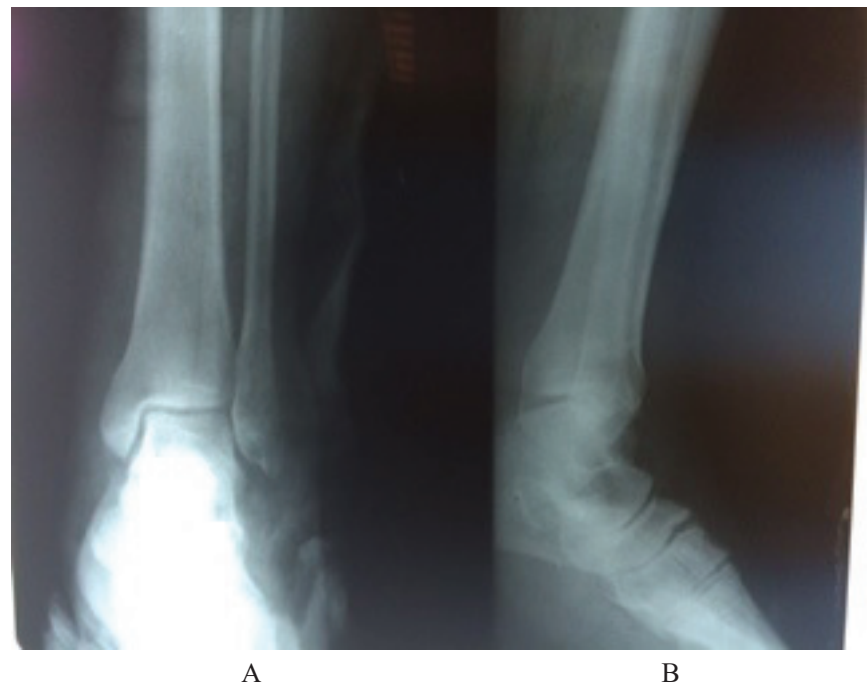

Fig. 2: Post-reduction radiographs - anterior-posterior (A) and lateral (B). 


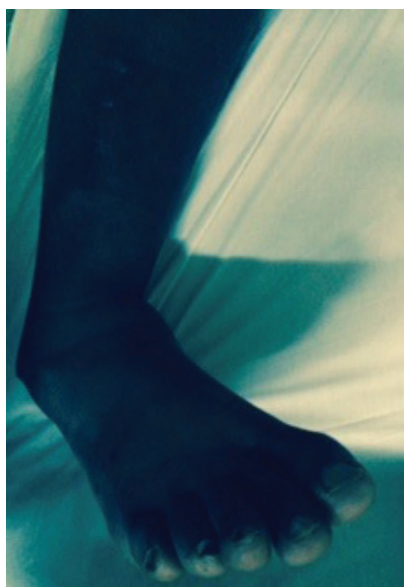

A

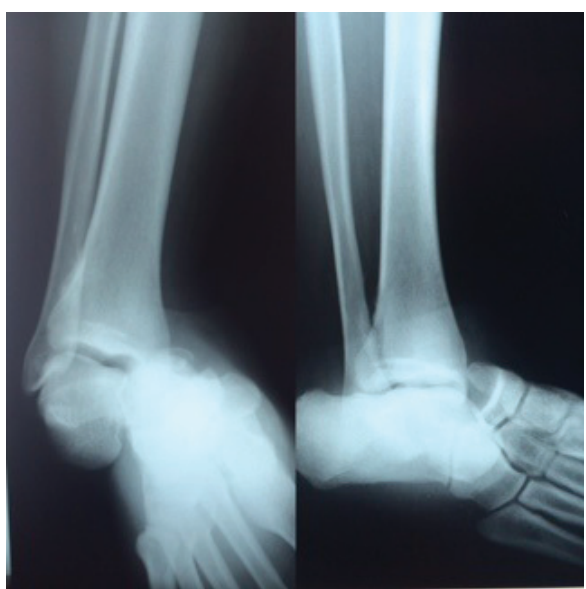

C

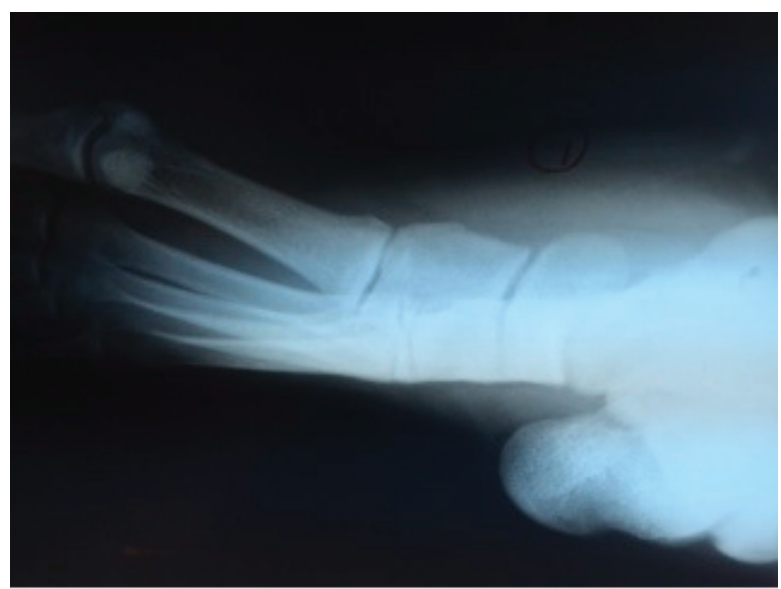

D

Fig. 3: Clinical radiograph of the right foot (A), anterior-posterior view of the right ankle (B), lateral view (C) and anterior-posterior radiograph of the foot (D).

A diagnosis of a medial subtalar dislocation was made, and closed reduction under conscious sedation was performed in the emergency room. Reduction was confirmed on plain radiography (Fig. 4). He was immobilized for three weeks, after which active range of motion was commenced. Weight-bearing was allowed at six weeks post-injury. At the two-year follow-up, he had pain-free ambulation, despite limitations in the range of motion at the subtalar joint.

\section{Case 3}

A 50-year-old man was involved in a motor vehicle accident while inebriated. He lost control of his

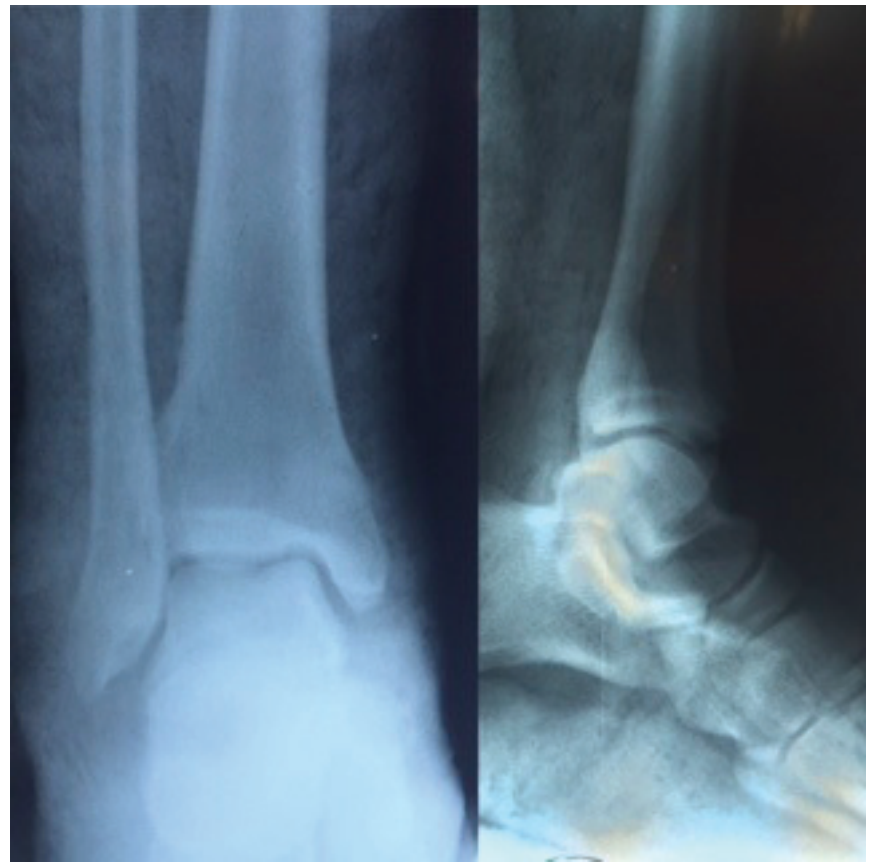

Fig. 4: Anterior-posterior and lateral radiographs of the right ankle postmanipulation. car and suffered a head-on collision with a truck. He presented with pain and gross deformity of the left ankle, as well as findings suggestive of blunt renal injury and mild traumatic brain injury. Plain radiographs revealed a comminuted fracture of the left lateral malleolus as well as disruption of both the talonavicular and talocalcaneal joints with a lateral subtalar dislocation (Fig. 5). The tibiotalar joint was intact. Manipulation under anaesthesia was attempted but unsuccessful.

A computed tomography (CT) scan of the foot and ankle was done. It revealed comminuted fractures to the lateral cuneiform, navicular, talus and head of the

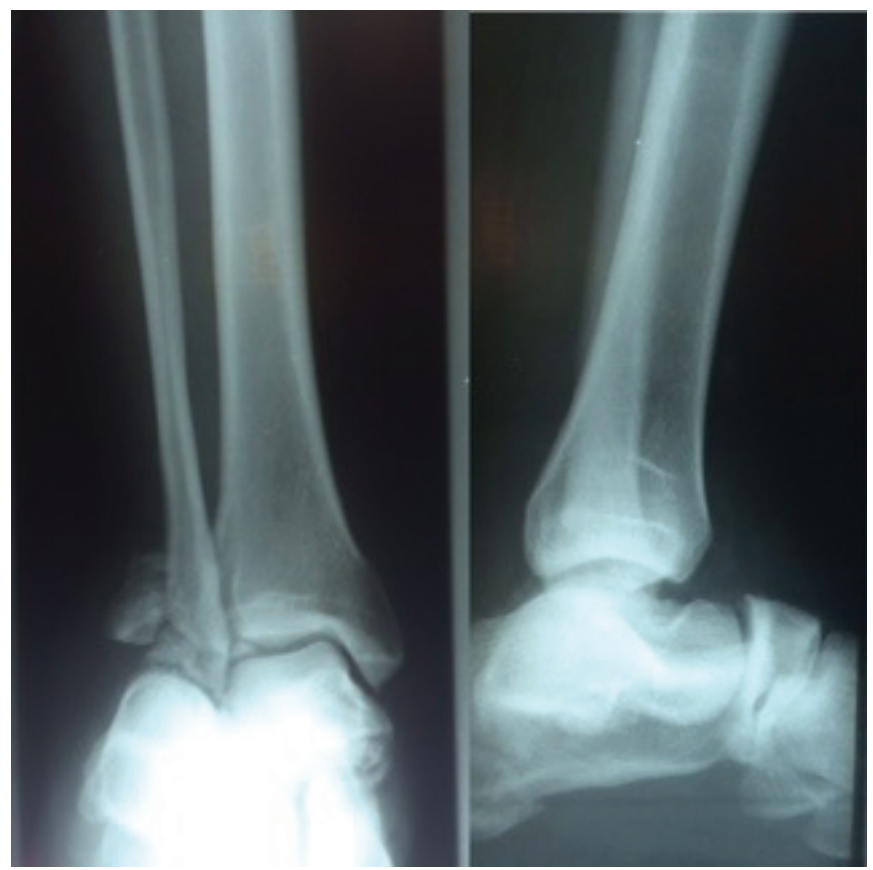

A

Fig. 5: Anterior-posterior (A) and lateral (B) radiographs of the right ankle. 
third metatarsal (Fig. 6). He was taken to the operating room where open reduction of the subtalar joint was undertaken and internal fixation of the navicular and lateral malleolus was done (Fig. 7). Intraoperatively, the talar head was found to be impacted in the calcaneus, and the tibialis posterior tendon was also interposed. Postoperatively, he was immobilized in a dorsal hemicast for four weeks, followed by active range of motion. One year post-initial injury, he continued to have swelling of the foot and occasional pain with ambulation and limitations in inversion and eversion at the subtalar joint.

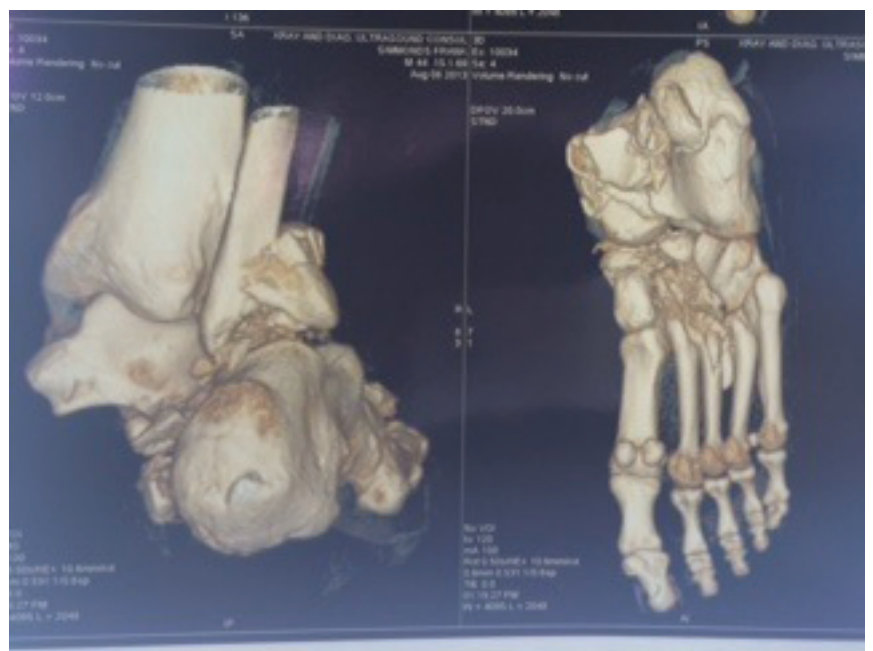

Fig. 6: Computed tomography scan with 3D reconstruction of the right foot and ankle.

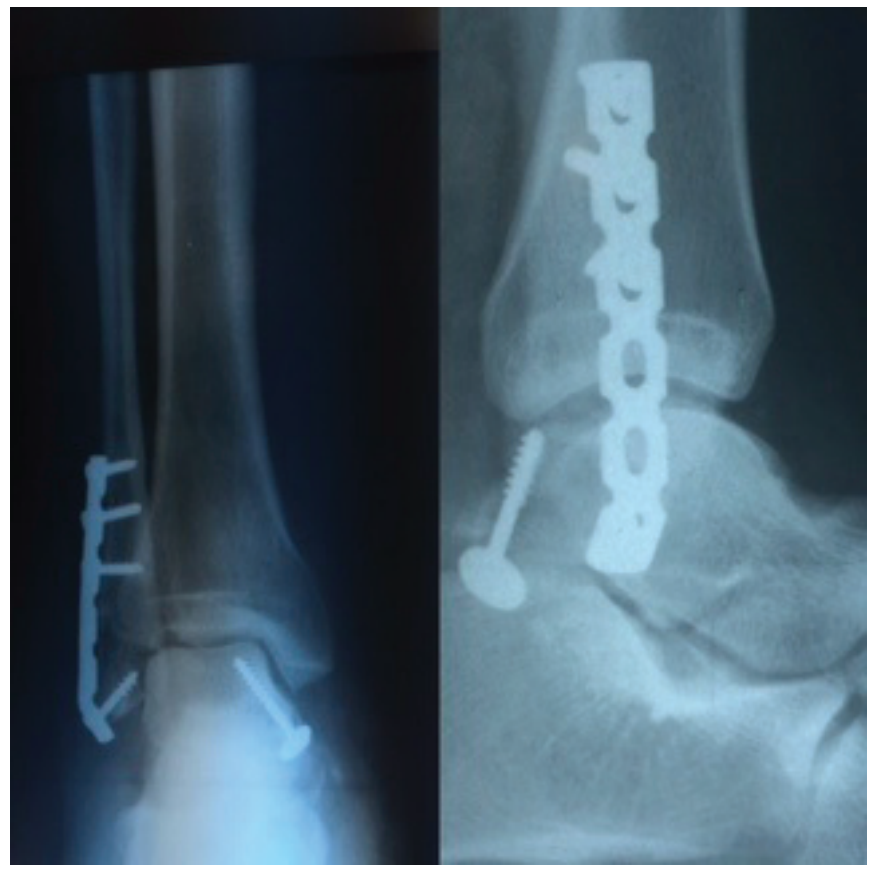

A

B

Fig. 7: Postoperative radiographs - anterior-posterior (A) and lateral (B) of the right ankle.

\section{Case 4}

A 40-year-old construction worker was standing on a ladder that started to slide down a 20-foot wall. His left foot became entangled in one of the rungs on the ladder while his right foot hung free as the ladder continued to descend down the wall. He subsequently started experiencing severe pain and swelling in his left foot and ankle with inability to weight-bear. Upon examination, significant findings were confined to his left foot. There was global swelling of the foot with slight puckering of the skin posterior medially but no gross deformity (Fig. 8).

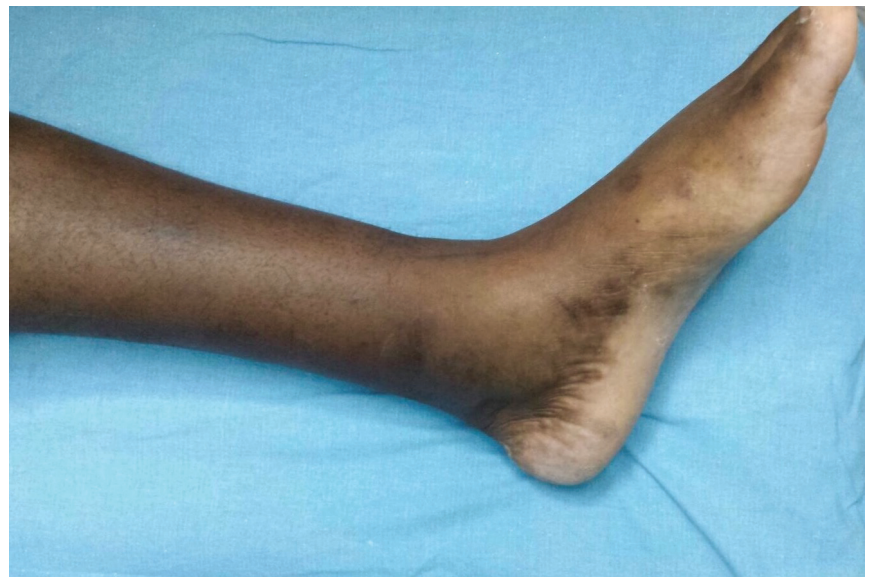

Fig. 8: Clinical radiograph showing puckering of the skin over the medial malleolus.

Tenderness was elicited over the second and third metatarsals. No distal neurovascular deficits were present. Radiographs revealed an anterior translation of the calcaneus in relation to the talus and disruption of the talonavicular joint with an intact tibiotalar joint (Fig. 9). There was no medial/lateral translation of the subtalar joint. Additionally, there were undisplaced fractures to the shaft of the second and third metatarsals.

A diagnosis of an anterior subtalar dislocation was made. Manipulation under conscious sedation was performed in the emergency room. An audible click was heard on reduction, and the same was confirmed with plain radiographs (Fig. 10). The foot was immobilized in a dorsal below knee hemicast and later replaced with a full cast. The full cast was maintained for six weeks in lieu of the metacarpal fractures. At the one-year followup, he had no limitations at the subtalar joint.

\section{DISCUSSION}

Subtalar dislocations, also known as peritalar and subastralagar dislocations, were first described by Judey and Dufaurest in 1811. They represent a complex dislocation of the talonavicular and talocalcaneal joints, while the 


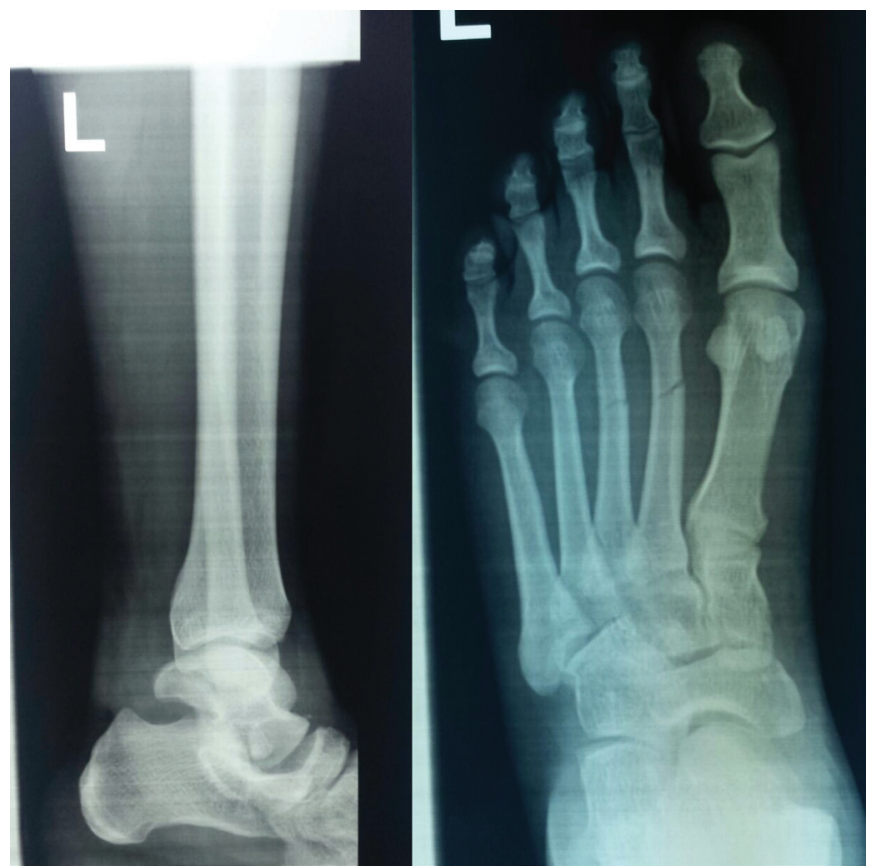

Fig. 9: Lateral radiographs of the ankle and anterior-posterior view of the foot showing a pure anterior subtalar dislocation.

tibiotalar and calcaneocuboid joints remain intact without an associated fracture of the neck of the talus $(1,2)$. They are a relatively rare injury, accounting for $1-2 \%$ of all joint dislocations (3). There are approximately 4.8 reported cases of subtalar dislocations per year (9).

The first classification of subtalar dislocations was by Broca in 1852 in which he described three types: inward, outward and backward. Four years later, Malgaigne and Beurger described an anterior dislocation and expanded the original classification. The present-day classification uses the nomenclature medial, lateral, anterior and posterior dislocation. Of these, the medial dislocation (Cases 1 and 2) is by far the most common, accounting for approximately $85 \%$ of the cases $(1,10)$. The lateral dislocation, as depicted in Case 3 , is the second most common, accounting for another $10-15 \%$ of the cases, and is usually as a result of high-energy trauma, as in this presentation. The posterior dislocation is the third most common while the anterior dislocation remains the least common.

Subtalar dislocations are usually due to high-energy mechanisms, namely, motor vehicle accidents and sport injuries. Sport injuries more often lead to a medial dislocation. In fact, Grantham ascribed the terminology 'basketball foot' to the medial subtype because five of his patients sustained their injuries while playing basketball (11).

The mechanism of injury often predicts the subtype of the dislocation. In medial subtalar dislocations, the

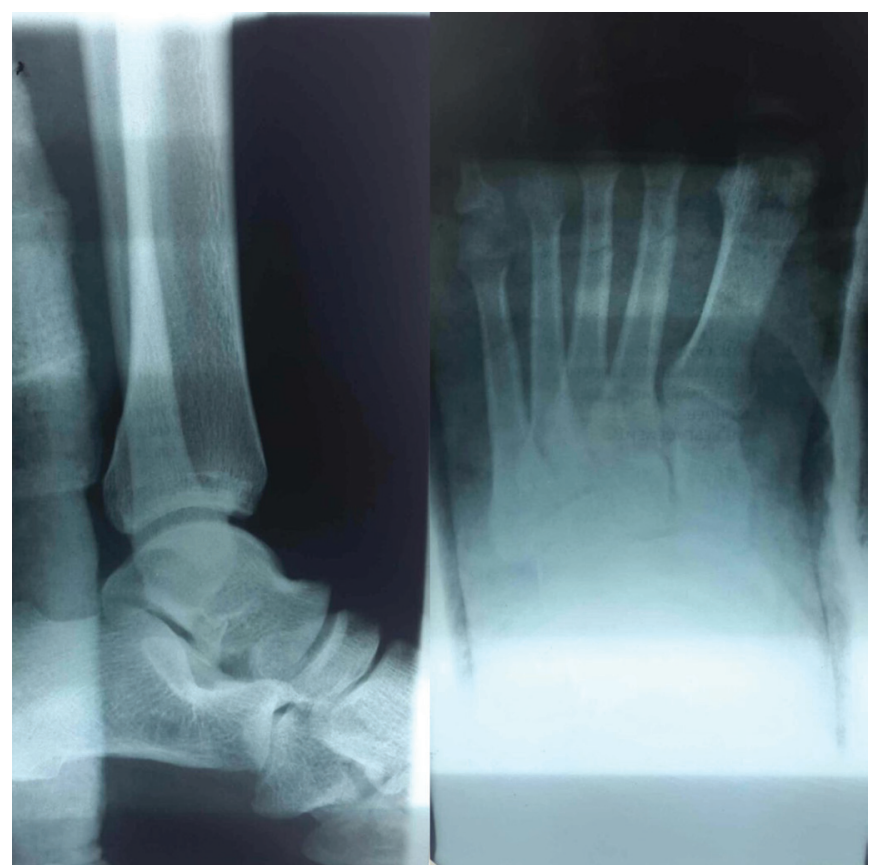

Fig. 10: Plain radiographs post-reduction showing the lateral ankle and anterior-posterior foot.

mechanism is thought to be excessive inversion with a plantar flexed foot. There is an initial disruption of the talonavicular joint, followed by rotatory subluxation of the subtalar joint. The sustentaculum tali then acts as a fulcrum for the talar neck, and the calcaneus is levered from beneath the talus $(12,13)$. On the other hand, lateral subtalar dislocations are due to forceful eversion of the plantar flexed foot with the talus levering around the anterior calcaneal process and resultant lateral dislocation of the calcaneus (10). Posterior subtalar dislocations are due to excessive plantar flexion of the foot while anterior dislocations are due to excessive dorsiflexion.

The clinical presentation is usually obvious with the foot locked in supination in the medial subtype, the socalled acquired club foot. The heel is medially displaced and in plantar flexion with tenting of the skin over bony prominences, namely, the lateral malleolus and talar head. In a lateral dislocation, the foot is locked in pronation and is also referred to as the acquired flat foot. The heel is displaced laterally with tenting of the skin over the talar head medially. The clinical presentation of the anterior and posterior subtypes is more subtle.

Plain radiographs are often sufficient to make the diagnosis. On the lateral radiograph, the position of the talar head is instructive. In the medial subtype, it lies superior to the navicular in keeping with the sequence of disruption. In the lateral subtype, it is inferior to the navicular or collinear. Lateral radiographs of a posterior dislocation reveal a superiorly displaced talus with the 
head resting on the navicular and the body within the subtalar facet of the calcaneus (14). In the case of the rare anterior dislocation, as in Case 4, the lateral radiograph showed an anteriorly displaced calcaneus, with the body of the talus stranded on the calcaneal tuber [Fig. 9] (4). However, the anterior-posterior radiograph of the ankle and foot shows an intact tibiotalar joint with a medial or lateral displacement of the calcaneus for medial and lateral subtypes, respectively. In the case of anterior or posterior dislocations, there is minimum displacement on the anterior-posterior projection [Fig. 9] (14).

Isolated subtalar dislocations, as in Cases 1 and 2, are rare as over $50 \%$ of medial subtalar dislocations and over $70 \%$ of lateral subtalar dislocations are associated with fractures as was the situation in Case 3 (1). A significant number of patients will go on to have a decreased range of motion in the subtalar joint as well as clinical and subclinical evidence of osteoarthritis (2). Authors have postulated that a number of associated injuries are missed on plain films ranging from chondral injuries to fractures. Bibbo et al demonstrated this in their review of nine patients in which CT scans revealed additional injuries in all nine patients (15). The authors further went on to recommend the routine use of CT scans in the evaluation of these patients as additional information gleaned may alter management (15).

Subtalar dislocations result in significant soft tissue injury, and the keystone to management includes early reduction. Closed reduction under conscious sedation can often be achieved in the emergency department. However, approximately $10 \%$ of medial dislocations and $15-20 \%$ of lateral dislocations (16) remain irreducible by closed manipulation. The blocks to reduction are usually due to bony impingement or soft tissue interposition.

In the lateral subtype, impediments to reduction include talar head impaction, entrapment of the joint capsule or, more superficial to these, the posterior tibial tendon. Flexor retinaculum, disruption facilitating draping of the talar head by the tendon, was proposed by Leitner in 1954 and was subsequently supported by cadaveric studies $(16,17)$. In medial subtalar dislocations, impediments to reduction may be due to talonavicular impaction, entrapment of the extensor retinaculum and deep peroneal nerve (18). Failure of closed reduction mandates urgent open reduction.

There is no consensus regarding the length of immobilization post-reduction, with recommendations for immobilization ranging from less than three weeks to more than four weeks $(1,12,19)$. Patient outcomes with this injury vary but can be predicted by the severity of the initial injury. A significant number of patients will have a decreased range of motion of the subtalar joint and radiographic evidence of arthrosis. The disability tends to be minimal, despite a significant loss of subtalar motion. Dislocations reduced by closed means tend to have a more favourable outcome, and the presence of an associated fracture is usually a marker for a poor outcome.

\section{CONCLUSION}

Subtalar dislocations remain an uncommon injury but, when seen, the clinical picture is usually dramatic, and a diagnosis is easily made. Urgent reduction is the keystone to effective management. A significant number of patients, approximately $50-80 \%$, will go on to have radiographic evidence of subtalar arthrosis $(9,19,20)$. This may be due to the presence of occult fractures and intra-articular fragments. Computed tomography scans may identify occult fractures not visualized on plain radiography. Identifying and addressing associated fractures, ie fixation or removal of intra-articular fragments, may improve the long-term prognosis.

\section{REFERENCES}

1. Zimmer TJ, Johnson KA. Subtalar dislocations. Clin Orthop Relat Res 1989; 238: 190-4.

2. Bohay DR, Manoli A II. Subtalar joint dislocations. Foot Ankle Int 1995; 16: 803-8.

3. Perugia D, Basile A, Massoni C, Gumina S, Rossi F, Ferretti A. Conservative treatment of subtalar dislocations. Int Orthop 2002; 26: 56-60.

4. Inokuchi S, Hashimoto T, Usami N. Anterior subtalar dislocation: case report. J Orthop Trauma 1997; 11: 235-7.

5. Shands AR. The incidence of subastragaloid dislocation of the foot with a report of one case of the inward type. J Bone Joint Surg 1928; 10: 306-13.

6. Thienhaus CO. Fracture of the astragalus with subastragaloid forward dislocation of the foot: removal of the entire astragalus. Ann Surg 1906; 43: 295-8.

7. Kanda T, Sakai H, Koseki K, Tamai K, Takeyama N, Saotome K. Anterior dislocation of the subtalar joint: a case report. Foot Ankle Int 2001; 22: 609-11.

8. Chuo CY, Lu CC, Liu PC, Shen WJ. Anterior subtalar dislocation: a case report. Kaohsiung J Med Sci; 2005; 21: 40-3.

9. Bohay DR, Manoli A II. Occult fractures following subtalar joint injuries. Foot Ankle Int 1996; 17: 164-9.

10. Monson ST, Ryan JR. Subtalar dislocation. J Bone Joint Surg Am 1981; 63: $1156-8$.

11. Grantham SA. Medical subtalar dislocation: five cases with a common etiology. J Trauma 1964; 4: 845-9.

12. Buckingham Jr WW, LeFlore I. Subtalar dislocation of the foot. J Trauma 1973; 13: 753-65.

13. Larsen HW. Subastragalar dislocation (luxatio pedis sub talo): a followup report of eight cases. Acta Chir Scand 1957; 113: 380-92.

14. Inokuchi $\mathrm{S}$, Hashimoto $\mathrm{T}$, Usami N. Posterior subtalar dislocation. J Trauma 1997; 42: 310-3. 
15. Bibbo C, Lin SS, Abidi N, Berberian W, Grossman M, Gebauer G et al. Missed and associated injuries after subtalar dislocation: the role of CT. Foot Ankle Int 2001; 22: 324-8.

16. Leitner B. Obstacles to reduction in subtalar dislocations. J Bone Joint Surg Am 1954; 36: 299-306.

17. Waldrop J, Ebraheim NA, Shapiro P, Jackson WT. Anatomical considerations of posterior tibialis tendon entrapment in irreducible lateral subtalar dislocation. Foot Ankle 1992; 13: 458-61.
18. Heck BE, Ebraheim NA, Jackson WT. Anatomical considerations of irreducible medial subtalar dislocation. Foot Ankle Int 1996; 17: 103-6.

19. DeLee JC, Curtis R. Subtalar dislocation of the foot. J Bone Joint Surg Am 1982; 64: 433-7.

20. Christensen SB, Lorentzen JE, Krogsoe O, Sneppen O. Subtalar dislocation. Acta Orthop Scand 1977; 48: 707-11. 